\title{
Interchange Trisomics of Pearl Millet (Pennisetum americanum (L.) K. Schum): Its Cytomorphology, Fertility and Transmission
}

\author{
U. P. Singh, R. Saikumar, R. M. Singh and R. K. Singh \\ Department of Genetics and Plant Breeding, \\ Institute of Agricultural Sciences, \\ Banaras Hindu University, \\ Varanasi-221005, India
}

Accpeted April 28, 1987

Literature on interchange trisomics in pearl millet is very limited as compared to reports available on primary trisomics (Burton and Powel 1968, Gill et al. 1970, Nameeta 1973, Saikumar et al. 1982, Singh et al. 1984). Narsingha Rao and Narayana Rao (1977) and Manga (1977) reported interchange trisomics in pearl millet which were isolated from different sources. Interchange trisomics are obtained in the progeny of translocation heterozygotes (Burnham 1962, Ramage 1960, 1963, Tsuchiya 1960, Khush 1973) as well as in the progeny of interchange trisomics (Singh et al. 1982). Besides their use in several studies of foundamental and practical importance, these trisomics constitute a good source of primary and tertiary trisomics (Khush 1973).

This paper for the first time reports on cytomorphology, fertility and transmission rate of 25 interchange trisomics obtained in the progeny of 6 translocation heterozygotes and of an interchange trisomic of pearl millet.

\section{Materials and methods}

Seeds obtained from an open-pollinated interchange trisomic of pearl millet were sown in pots during 1982. Out of 210 seeds sown, 37 plants were trisomics, 8 of them interchange trisomics and the remaining disomics. Similarly, 17 more interchange trisomics were isolated in the progeny of 6 different translocation heterozygotes of pearl millet. The morphology and fertility of all these trisomics were recorded and only 18 trisomics could be studied in following three seasons of the crop (1983, 1984 and 1985) for analysis of their cytological behaviour and transmission frequency. Material for cytological analysis was fixed in a freshly prepared Carnoy's fluid for 24 hours at room temperature and then stored in $70 \%$ alcohol until further study. Anthers were squashed in $2.0 \%$ acetocarmine and fresh preparations were used for study of various chromosome configurations and microphotography.

\section{Results}

\section{Morphology and fertility}

The trisomics plants were weak, slender with short, narrow leaves and small panicles as compared to normal disomics. They also had a high degree of pollen and ovule fertility (Table 1). A considerable variation from plant to plant within each trisomic class occurred with regard to plant height, number of tillers, leaf length and panicle length, indicating heterozygous nature of parental sources of these trisomics.

In the trisomic set derived from an interchange trisomic source, the maximum pollen and ovule fertility was displayed by $\operatorname{Tr}-69(40.1 \%$ and $50.6 \%$, respectively) followed by $\operatorname{Tr}-43$ $(37.7 \%$ and $47.5 \%)$ and $\operatorname{Tr}-18(21.3 \%$ and $40.0 \%)$ in descending order of magnitude. And 
the remaining 5 trisomics showed a low degree of pollen and ovule fertility. Thus, based on these considerations and on certain morphological traits, the 8 trisomics obtained in this class could be classified in two groups: the first group consisting of $\operatorname{Tr}-18,-43$ and -69 and the second group consisted of $\operatorname{Tr}-20,-34,-48,-65$ and -84 . Similar variation pattern was recorded with stocks derived from same as well as from different interchange heterozygotes of pearl millet (Table 1). The maximum pollen and ovule fertility was recorded in $\operatorname{Tr}-540(74.0 \%$ and $95.0 \%)$ followed by $\operatorname{Tr}-663,-424$ and -704 whereas the lowest pollen and ovule fertility was seen in $\operatorname{Tr}-645(2.3 \%$ and $2.0 \%)$.

Table 1. Morphological characteristics of different interchange trisomics of pearl millet

\begin{tabular}{|c|c|c|c|c|c|c|c|}
\hline $\begin{array}{l}\text { Trisomic } \\
\text { number }\end{array}$ & Source & $\begin{array}{l}\text { Plant } \\
\text { height } \\
\text { (cm) }\end{array}$ & $\begin{array}{l}\text { No. of } \\
\text { tillers }\end{array}$ & $\begin{array}{c}\text { Leaf } \\
\text { length } \\
(\mathrm{cm})\end{array}$ & $\begin{array}{c}\text { Panicle } \\
\text { length } \\
\text { (cm) }\end{array}$ & $\begin{array}{c}\text { Pollen } \\
\text { fertility } \\
(\%)\end{array}$ & $\begin{array}{c}\text { Ovule } \\
\text { fertility } \\
(\%)\end{array}$ \\
\hline $\operatorname{Tr}-18$ & IT & 109.0 & 36.0 & 27.7 & 16.1 & 21.3 & 40.0 \\
\hline $\operatorname{Tr}-20$ & $\mathrm{IT}$ & 83.0 & 5.5 & 30.6 & 10.1 & 34.2 & 5.3 \\
\hline Tr-34 & IT & 86.4 & 15.0 & 25.0 & 17.0 & 10.0 & 2.0 \\
\hline $\operatorname{Tr}-43$ & IT & 98.0 & 19.0 & 33.0 & 10.3 & 37.7 & 47.5 \\
\hline $\operatorname{Tr}-48$ & $\mathrm{IT}$ & 59.5 & 3.0 & 30.0 & 10.0 & 4.3 & 5.0 \\
\hline $\operatorname{Tr}-65$ & $\mathrm{IT}$ & 86.2 & 11.0 & 29.6 & 10.0 & 6.9 & 20.0 \\
\hline $\operatorname{Tr}-69$ & IT & 72.6 & 3.0 & 32.0 & 10.5 & 40.1 & 50.6 \\
\hline $\operatorname{Tr}-84$ & $\mathrm{IT}$ & 88.0 & 35.0 & 31.0 & 9.5 & 16.5 & 10.0 \\
\hline $\operatorname{Tr}-802$ & TH-2 & 87.4 & 49.3 & 29.2 & 15.2 & 30.9 & 43.2 \\
\hline Tr-396 & TH-4 & 89.0 & 3.0 & 39.5 & 15.5 & 19.3 & 16.0 \\
\hline $\operatorname{Tr}-632$ & TH-4 & 70.0 & 14.0 & 24.2 & 11.0 & 28.4 & 45.0 \\
\hline $\operatorname{Tr}-663$ & TH-4 & 45.0 & 51.0 & 19.7 & 12.0 & 72.2 & 80.0 \\
\hline $\operatorname{Tr}-424$ & TH-5 & 61.0 & 7.0 & 24.0 & 24.0 & 52.6 & 70.0 \\
\hline $\operatorname{Tr}-478$ & TH-5 & 88.7 & 9.1 & 35.3 & 12.6 & 7.8 & 46.0 \\
\hline $\operatorname{Tr}-540$ & TH-5 & 73.0 & 20.0 & 36.0 & 12.0 & 74.0 & 95.0 \\
\hline $\operatorname{Tr}-543$ & TH-5 & 115.8 & 17.4 & 39.1 & 14.6 & 20.6 & 16.3 \\
\hline $\operatorname{Tr}-624$ & TH-5 & 90.0 & 5.0 & 42.0 & 17.0 & 2.8 & 6.0 \\
\hline Tr-704 & TH-5 & 108.0 & 13.0 & 38.0 & 14.0 & 42.6 & 70.0 \\
\hline $\operatorname{Tr}-172$ & TH-6 & 97.0 & 70.0 & 25.7 & 17.3 & 8.4 & 6.0 \\
\hline $\operatorname{Tr}-374$ & TH-6 & 62.0 & 24.0 & 26.2 & 11.5 & 3.9 & 2.0 \\
\hline Tr-591 & TH-6 & 85.0 & 5.0 & 14.0 & 13.0 & 46.6 & 10.0 \\
\hline $\operatorname{Tr}-606$ & TH-6 & 86.4 & 43.0 & 44.2 & 13.8 & 3.3 & 2.0 \\
\hline $\operatorname{Tr}-753$ & TH-6 & 88.0 & 65.0 & 26.5 & 10.7 & 24.5 & 20.0 \\
\hline $\mathrm{Tr}-421$ & TH-7 & 83.9 & 24.3 & 53.8 & 12.8 & 30.0 & 26.5 \\
\hline \multirow[t]{2}{*}{ Tr -645} & TH-8 & 96.0 & 22.0 & 35.0 & 17.0 & 2.3 & 2.0 \\
\hline & Normal & 124.6 & 3.3 & 49.3 & 26.8 & 90.0 & 95.6 \\
\hline
\end{tabular}

Note: $\quad$ IT $=$ interchange trisomic

$\mathrm{TH}=$ translocation heterozygote.

\section{Cytology}

Several kinds of chromosome associations were observed at diakinesis and MI (Figs. 1 to 7). There were univalents, trivalents, chain of four $+1^{I}$ or $\odot_{4}+1^{1}$ or chain of five, along with certain bivalents. The presence of $\odot_{4}+1^{1}$ and a complete absence of dumb-bell shaped pentavalents in meiotic cells confirms the interchange trisomic nature of these stocks. The frequency of each type of association and configurations observed in different trisomics is given in Table 2. A number of interchange trisomics, such as, Tr-663, $-421,-18,-753$ and -20 , recorded a high frequency of cells containing $6^{1 I}+1^{I I I}$ (Fig. 4). The remaining trisomics showed an association of $7^{\mathrm{II}}+1^{\mathrm{I}} /$ cell in a higher percentage of PMCs. But the configurations of $\sigma_{4}+1^{\mathrm{I}}$ (Figs. 1,6) or chain of four $+1^{\text {I }}$ (Figs. 2,5 ) could be observed invariably in all the stocks of 
interchange trisomics. Other types of configurations were relatively infrequent. A considerable percentage of PMCs were seen with chain of five (Fig. 7) in every stock of interchange trisomics. In this study, the average percentage of trivalents, univalents, quadrivalents and pentavalents along with certain bivalents, calculated over trisomics, was $38.7 \%, 21.8 \%, 22.0 \%$ and $17.6 \%$, respectively (Table 2). PMCs with $6^{\mathrm{II}}+3^{\mathrm{I}}$ were infrequent (ave. $1.9 \%$ ). Various shapes of pentavalents were noticed in different interchange trisomics of pearl millet. On an

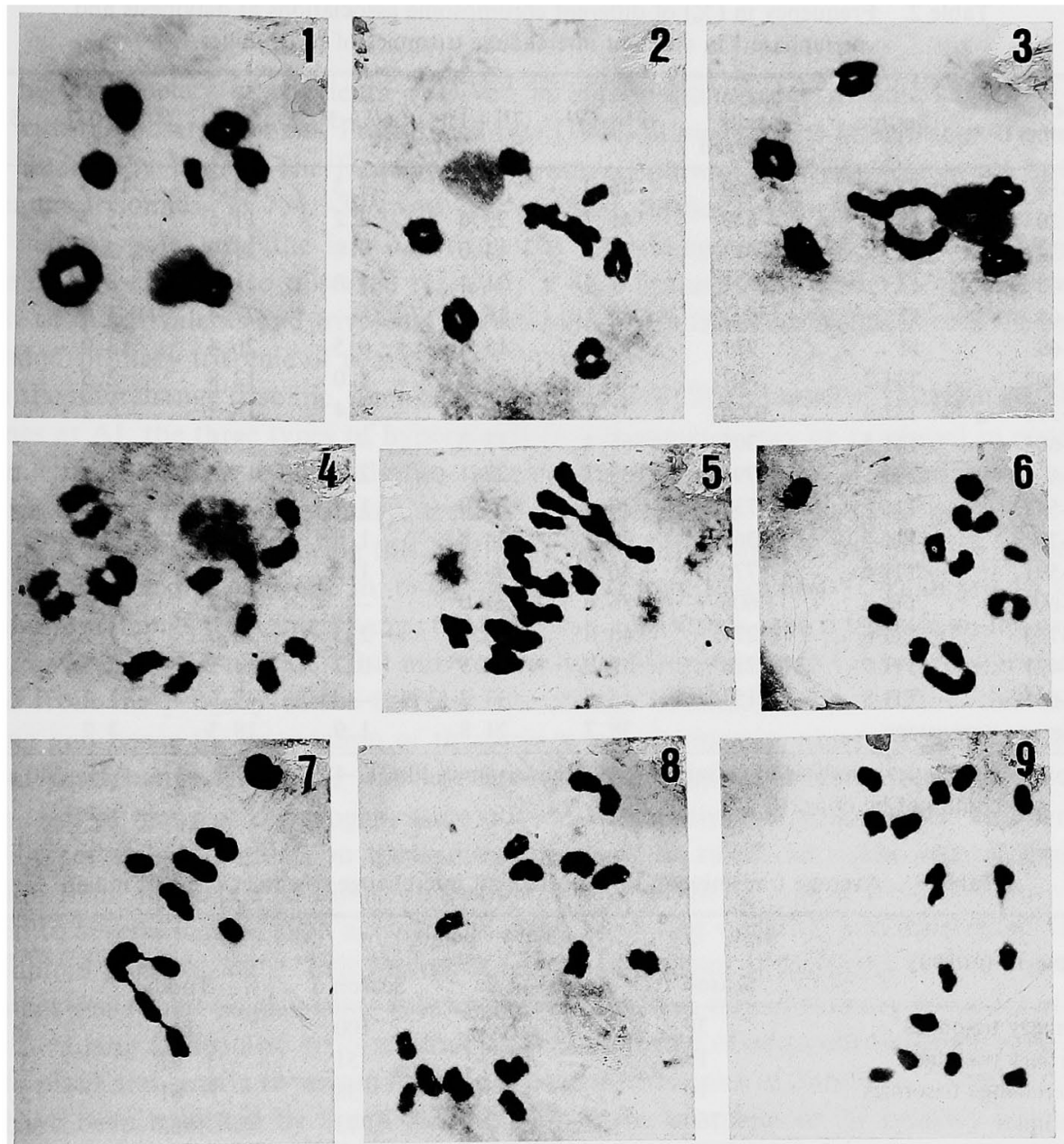

Figs. 1-9. Chromosome associations at diakinesis and metaphase I and distribution at anaphase $\mathrm{I}$ in interchange trisomics of pearl millet. 1 , diakinesis $5^{\mathrm{II}}+1^{\odot} 4+1^{\mathrm{I}}$. 2 , diakinesis, $5^{\mathrm{II}}+1^{\mathrm{IV}}$ (double X-shaped) $+1^{1} .3$, diakinesis, $5^{{ }^{I I}}+1^{{ }^{\mathrm{IV}}}$ (quadrivalent attached with univalent). 4, diakinesis, $6^{\text {II }}+1^{\text {III }}$ (bowl-shaped). 5, metaphase I, $5^{\text {II }}+1^{\text {IV }}$ (Y-shaped) $+1^{\mathrm{I}} .6$, metaphase I, $4^{\mathrm{II}}+1^{\odot} 4$ $+3^{\mathrm{I}}$. 7, metaphase I, $4^{\mathrm{II}}+2^{\mathrm{I}}+\mathbf{1}^{\mathrm{V}}$ (J-shaped). 8, anaphase I, 9:6 distribution. 9, anaphase I, 8: 7 distribution.

average, the maximum frequency of PMCs were seen with chain shaped pentavalents $(83.76 \%)$ followed by pan- $(8.11 \%$ ), quadrivalent attached with univalent (Fig. $3 ; 5.12 \%)$, U- (1.28\%), Y- $(0.85 \%)$ and J- shaped (Fig. $7 ; 0.85 \%)$ configurations in descending order of magnitude. Similarly, trivalents observed at MI were also of different types, such as, chain-, V-, pan-, J-, X-, bowl- (Fig. 4), L-, Y-, Z- and S- shapes where chain shaped trivalents were most frequent $(67.12 \%)$ followed by $\mathrm{V}-(18.88 \%)$ and pan shapes $(6.56 \%)$. Other shapes were relatively less frequent. 
There was not much variation in mean chiasmata frequency between trisomics and disomics. However, the average number of chiasmata/cell ranged between 10.00 to 13.56 noticed in different trisomics of pearl millet. Relatively more number of chiasmata were recorded in those trisomics where trivalents and quadrivalents were highly frequent. Average chiasmata/ bivalent ranged between 1.48 to 1.92 .

Table 2. Frequency in $(\%)$ of different chromosome associations at diakinesis and metaphase $I$ in different interchange trisomics of pearl millet

\begin{tabular}{|c|c|c|c|c|c|c|c|c|}
\hline $\begin{array}{l}\text { Trisomic } \\
\text { number }\end{array}$ & Source & $\begin{array}{l}\text { No. of } \\
\text { cells } \\
\text { analysed }\end{array}$ & $6^{I I}+1^{11 I}$ & $7^{1 \mathrm{II}}+1^{\mathrm{I}}$ & $6^{\mathrm{II}}+3^{\mathrm{I}}$ & $\begin{array}{c}5^{11}+ \\
1 \oplus 4+1^{1}\end{array}$ & $\begin{array}{l}5^{\mathrm{II}}+ \\
1^{1 \mathrm{~V}}(\mathrm{C}) \\
+1^{\mathrm{I}}\end{array}$ & $5^{I I}+1^{v}$ \\
\hline Tr-18 & IT & 260 & 46.0 & 12.8 & 1.3 & 14.7 & 15.3 & 10.2 \\
\hline $\operatorname{Tr}-20$ & IT & 649 & 41.7 & 23.6 & 2.2 & 11.5 & 3.7 & 17.5 \\
\hline $\operatorname{Tr}-34$ & IT & 1013 & 38.5 & 14.0 & 0.8 & 31.9 & 2.7 & 12.2 \\
\hline $\operatorname{Tr}-43$ & IT & 1027 & 31.4 & 31.4 & 1.8 & 11.0 & 3.0 & 21.8 \\
\hline $\operatorname{Tr}-65$ & IT & 822 & 33.1 & 16.8 & - & 27.4 & 4.0 & 18.8 \\
\hline $\operatorname{Tr}-69$ & IT & 921 & 39.4 & 13.8 & 0.5 & 26.4 & 3.0 & 17.1 \\
\hline Tr-802 & TH-2 & 807 & 35.7 & 26.0 & 2.0 & 12.8 & 2.5 & 19.8 \\
\hline $\operatorname{Tr}-396$ & TH-4 & 1066 & 31.7 & 25.6 & 2.4 & 15.2 & 3.2 & 22.2 \\
\hline $\operatorname{Tr}-663$ & TH-4 & 305 & 65.4 & 17.2 & - & 5.1 & - & 12.4 \\
\hline $\operatorname{Tr}-478$ & TH-5 & 791 & 33.1 & 27.1 & 2.6 & 13.3 & 2.8 & 21.2 \\
\hline Tr-543 & TH-5 & 738 & 36.6 & 22.0 & 1.7 & 20.9 & 3.0 & 16.0 \\
\hline $\operatorname{Tr}-704$ & TH-5 & 1361 & 34.3 & 24.8 & 1.6 & 12.7 & 2.4 & 24.5 \\
\hline $\operatorname{Tr}-591$ & TH-6 & 770 & 36.6 & 34.9 & 1.5 & 7.5 & 7.2 & 12.5 \\
\hline Tr-606 & TH-6 & 606 & 36.6 & 24.0 & - & 24.1 & 4.4 & 11.1 \\
\hline $\operatorname{Tr}-753$ & TH-6 & 271 & 43.8 & 16.7 & 2.5 & 18.0 & 1.7 & 17.6 \\
\hline $\operatorname{Tr}-421$ & TH-7 & 716 & 49.0 & 18.5 & 0.7 & 14.5 & 2.5 & 14.6 \\
\hline $\operatorname{Tr}-645$ & TH-8 & 153 & 18.5 & 13.2 & - & 47.6 & 3.2 & 17.6 \\
\hline \multicolumn{2}{|c|}{ Average percentage } & & 38.7 & 21.8 & 1.9 & 18.3 & 3.7 & 17.6 \\
\hline
\end{tabular}

Note: Cytological analysis of certain interchange trisomics like Tr-48, $-84,-772,-374,-424,-540$ and -624 could not be done.

Table 3. Average transmission rate of different interchange trisomics of pearl millet

\begin{tabular}{|c|c|c|c|c|c|}
\hline \multirow{2}{*}{ Types of progeny } & \multicolumn{4}{|c|}{ Number of plants } & \multirow{2}{*}{$\%$} \\
\hline & Season 1 & Season 2 & Season 3 & Total & \\
\hline Primary trisomics & 39 & 7 & 100 & 146 & 6.61 \\
\hline Tertiary trisomics & 19 & 17 & 51 & 87 & 3.82 \\
\hline Interchange trisomics & 10 & 13 & 38 & 61 & 2.67 \\
\hline Disomics & 760 & 450 & 773 & 1983 & 36.90 \\
\hline Total & 828 & 487 & 962 & 2277 & \\
\hline
\end{tabular}

There was a regular distribution of $8: 7$ (Fig. 9) at AI except in a few PMCs which showed late disjunction of a bivalent and formation of laggards. The 9:6 distribution (Fig. 8) was a rare event.

\section{Transmission}

The transmission rate of extra chromosome varied from plant to plant and season to season for the same trisomic. For example, an interchange trisomic isolated in 1982 gave $31.3 \%$ trisomics in the progeny but some of the interchange trisomics derived from the same stock showed a poor rate of trisomic transmission $(0$ to $5 \%$ ) in the next season of crop. An observation of the rate of transmission and types of progeny produced in different interchange 
trisomics when tested over three seasons reveals that there was a considerable variation from one season to other with regards to ratio obtained for normal disomics, primary, tertiary and interchange trisomics of pearl millet (Table 3). When data of different stocks were pooled over seasons, the progeny consisted of $86.9 \%$ disomics, $6.61 \%$ primary, $3.82 \%$ tertiary and $2.67 \%$ interchange trisomics.

\section{Discussion}

A high frequency of trivalents observed in all the interchange trisomics of pearl millet agrees with the observations of Prasad and Das (1975) in most of the interchange trisomics of barley studied by them. The frequency of pentavalents was relatively less in all but three interchange trisomics, $\mathrm{Tr}-754,-396$ and -43 ; of them, former two were derived from translocation heterozygotes and the last one from the interchange trisomic. Narsingha Rao and Narayana Rao (1977) also observed relatively a high frequency of pentavalents as compared to those of quadrivalents and trivalents in two interchange trisomics isolated from the progeny of 'slender' primary trisomic of pearl millet.

In the interchange trisomic, on account of unequal ( $8: 7)$ and random distribution of chromosomes at $\mathrm{AI}$, the three types of hyperploids $(n+1)$ gametes may be produced in equal proportion. If all of them are equally functional and fertilized by normal pollen, three types of trisomics can be produced-primary, tertiary and interchange in the ratio of $1: 1: 1$ in the following generation. Following this, out of 37 trisomics isolated in the progeny of an openpollinated interchange trisomic in 1982, 14 were primary trisomics, 12 belonged to tertiary class and remainings were interchange trisomics in nature which gave a close fit to the expected ratio $\left(\chi^{2}=0.38, \mathrm{p}=0.8\right.$ to 0.9$)$. But most of the interchange trisomics (including some of those derived from the progeny of the foresaid interchange trisomic) did not follow this mode of breeding and hence the proportion of the three types of trisomics observed in the progeny of different interchange trisomics, was not equal in each season of the crop. However, the sample sizes of many of the progeny were not ideal for analysis of transmission and hence the possibility of sampling effect on transmission can not be ruled out. The overall significant deviation from the expected mode of trisomic transmission $\left(\chi^{2}=38.6, p=0.001\right)$ may be attributed to several causes, such as, seasonal effect, sampling variation and differential viability of aneuploid gametes, etc. This finding is in line with those of Rajhathy (1975) wherein environment was found to play some role on the transmission rate of primary trisomics of Avena strigosa. Liang (1979) also reported that transmission rate of extra chromosome varied from plant to plant and season to season for the six primary trisomics of Sorghum. Similar observations have been recorded by Singh et al. (1984) in the complete set of primary trisomics of pearl millet. Further, in the first and third seasons, though the overall sample sizes were relatively higher; primary trisomics were more frequent than the other trisomics; whereas the observed ratio of primary, tertiary and interchange trisomics did not deviate significantly from the expected one $\left(\chi^{2}=4.11, \mathrm{p}=0.10\right.$ to 0.20$)$ inspite of small sample size found in the second season of the crop. It appears that besides seasonal effect and sampling variation contributing to the transmission frequency, other factors like differential viability of aneuploid gametes $(n+1)$ and zygotes $(2 n+1)$ produced from interchange trisomic, also caused considerable variation in the transmission rate of extra chromosome. On an average, a higher precentage of primary trisomics obtained in the progeny of interchange trisomics might have resulted from the greater viability of gametes and zygotes with an extra primary chromosome of the set. It may be inferred that addition of primary chromosome in the total complement possibly causes less genetic imbalance than that of other types of chromosomes. This observation is consistent with those of Singh et al. (1982) wherein tertiary trisomics were found to be transmitted less 
oftenly than that of primary trisomics in the progeny of tertiary trisomics of pearl millet. In addition, the differential viability of subnormal zygote of primary trisomic and highly abnormal zygotes of interchange trisomic having two interchange chromosomes might have also affected the transmission rate of extra chromosome.

\section{Summary}

Twenty five interchange trisomics were isolated from an interchange trisomic and six translocation heterozygotes of pearl millet $(2 n=14)$. Morphology and fertility of these trisomics varied from plant to plant and season to season. Cytological analysis of these trisomics indicates that chromosome associations of trivalents and univalents were frequent with comparatively less frequency of $\odot_{4}$ and pentavalents in all the trisomics studied. Other associations were relatively infrequent. Transmission rate and breeding behaviour of 18 interchange trisomics were studied for three seasons of the crop and it was found that average frequency of primary trisomics was more than that of other trisomics (tertiary and interchange). The possible causes of differential transmission rates of different trisomics have been discussed.

\section{References}

Burnham, C. R. 1962. Discussions in Cytogenetics. Burgess Publishing Company. Mineapolis, U.S.A. Burton, G. W. and Powel, J. B. 1968. Pearl millet breeding and cytogenetics. Adv. Agron. 20: 49-98.

Gill, B. S., Virmani, S. S. and Minocha, J. L. 1970. Primary trisomics in pearl millet. Can. J. Genet. 12: 474 483.

Khush, G. S. 1973. Cytogenetics of Aneuploids. New York Acad. Press.

Liang, G. H. 1979. Trisomic transmission in six primary trisomics of Sorghum. Crop Sci. 19: 339-344.

Manga, V. 1977. Interchange trisomics in pearl millet. Experientia 33: 1581-1582.

Nameeta, N. 1973. Establishment of aneuploids and their use in pearl millet (Pennisetum americanum (L.) K. Schum) improvement. Ph. D. Thesis submitted in Meerut University, India.

Narsingha Rao, P. S. R. L. and Narayana Rao, I. 1977. Two interchange trisomics in pearl millet. Curr. Sci. 47: 314-315.

Prasad, G. and Das, K. 1975. Interchange trisomics in a 6-rowed barley. Cytologia 40: 627-632.

Rajhathy, T. 1975. Trisomics of Avena strigosa. Can. J. Genet. 17: 151-166.

Ramage, R. T. 1960 . Trisomics from interchange heterozygotes in barley. Agron. J. 52: 156-159.

- 1963. Chromosome associations and their use in genetics and breeding-translocations. Proc. Ist Int. Barley Genet. Symp. Wageningen Barley Genet. 1: 99-115.

Saikumar, R., Singh, U. P., Singh, R. B. and Singh, R. M. 1982. Cytomorphological behaviour of primary trisomics in pearl millet (Pennisetum americanum (L.) K. Schum). Cytologia 43: 503-510.

Singh, U. P., Saikumar, R., Singh, R. M. and Singh, R. B. 1982. Tertiary trisomics of pearl millet (Pennisetum americanum (L) K. Schum: Its cytomorphology, fertility and transmission. Theor. Appl. Genet. 63: 139-144.

-, -, Singh, R. B. and Singh, R. M. 1984. Transmission of primary trisomics in pearl millet. Theor. Appl. Genet. 67: 135-142.

Tsuchiya, T. 1960. Cytogenetic studies of trisomics in barley. Jap. J. Bot. 17: 177-213. 